\title{
Role of self-organising myddosome oligomers in inflammatory signalling by Toll-like receptors
}

Nicholas J. Gay

\begin{abstract}
A paper published in BMC Biology characterises biophysically oligomeric and filamentous structures formed spontaneously by the Toll-like receptor signalling adaptor MyD88. Naturally occurring mutants of MyD88 that cause immunodeficiency are unable to form these structures. By contrast a somatic mutant that promotes the survival of tumour cells forms oligomers much more readily than the wild-type protein. These findings suggest that assembly of oligomeric MyD88 is critical for the regulation of inflammatory signalling.
\end{abstract}

\section{Commentary}

Innate immune and inflammatory signalling underlie a large burden of human disease ranging from sepsis to rheumatoid arthritis and neuronal degeneration. Thirty years ago Charles Janeway correctly predicted a central role in these signalling processes for what he termed pattern recognition receptors (PRRs), germline-encoded molecules that recognise conserved structures associated with microbial pathogens (PAMPS). One important group of PRRs is the Toll-like receptors (TLRs). These molecules respond, broadly speaking, to non-self lipids and nucleic acids presented at the cell surface or in endosomes, respectively (Fig. 1). Because of their central role in inflammatory signalling the molecular mechanisms of signal transduction by TLRs are of considerable interest and are therapeutic targets for novel antiinflammatory medicines [1].

PAMPs, such as lipopolysaccharide (LPS) from Gramnegative bacteria, bind directly to TLRs to induce

Correspondence: njg11@cam.ac.uk

Department of Biochemistry, University of Cambridge, Cambridge CB2 1GA UK

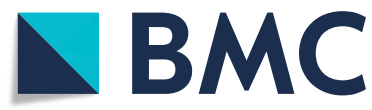

formation of an active dimeric complex. Dimerization of the cytosolic TIR domains provides a transient nucleation signal for the assembly of an oligomeric scaffold, the myddosome, that is required for downstream signal transduction [2, 3]. The myddosome consists of the signal transducer MyD88 and IRAK kinases (Fig. 2). It has an unusual and variable stoichiometry of six to eight MyD88, four IRAK4 and four IRAK2 subunits [4]. A paper published in this issue of BMC Biology by Gambin and colleagues [5] provides new insights into how this complex may be assembled.

MyD88 consists of two modules, a death domain (DD) and a TIR domain. Dimerisation of the TLR TIR domains creates a new binding surface that can interact with the corresponding TIR domains of MyD88, nucleating the assembly of a closed myddosome complex. In resting cells it is thought that MyD88 is auto-inhibited, perhaps by interactions between the TIR and death domains. Transient interaction with the activated receptor is viewed as relieving this inhibition, allowing the formation of the helical myddosome assembly [6].

In the present study the authors have used an in vitro system to produce full-length MyD88 and in addition the isolated DD and TIR domain. This allows protein to be produced in a controlled manner and single molecule fluorescence methods were then used to assay the aggregation propensity of DDs, TIR domains and full-length MyD88. This analysis reveals that, at nanomolar concentrations, full-length MyD88 is able to form large polymers or filaments whereas only short oligomers of TIR domains are detected. At this low concentration the DD is also able to form oligomers, although these are much smaller than the polymers formed by the full-length protein.

Two mutations in MyD88 that cause immune deficiency in humans were then tested for their effect on the propensity of full-length MyD88 to oligomerise. Both of these, one in the DD and one in the TIR

C The Author(s). 2019 Open Access This article is distributed under the terms of the Creative Commons Attribution 4.0 International License (http://creativecommons.org/licenses/by/4.0/), which permits unrestricted use, distribution, and reproduction in any medium, provided you give appropriate credit to the original author(s) and the source, provide a link to the Creative Commons license, and indicate if changes were made. The Creative Commons Public Domain Dedication waiver (http://creativecommons.org/publicdomain/zero/1.0/) applies to the data made available in this article, unless otherwise stated. 


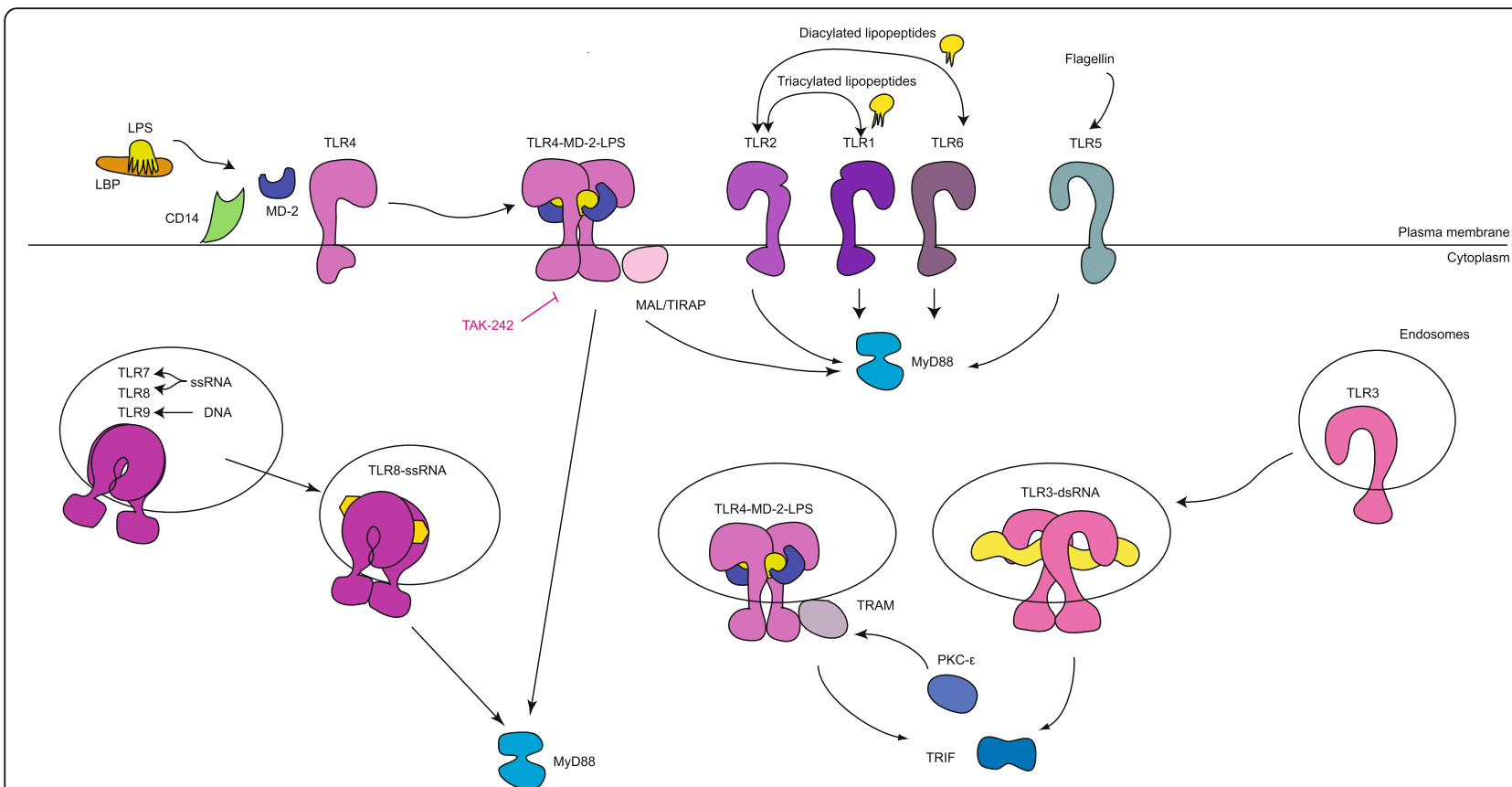

Fig. 1. Overview of immune response signalling by Toll-like receptors. Toll-like receptors (TLRs) are present on the cell surface and in endosomes, where they detect microbial cell-wall components, non-self nucleic acids, or danger-associated self molecules. Upon stimulation, TLRs activate pathways that involve myeloid differentiation primary response protein 88 (MYD88) and/or TIR domain-containing adaptor protein inducing IFN $\beta$ (TRIF). MYD88 and TRIF nucleate signalling scaffolds, known respectively as myddosomes and triffosomes, that recruit kinases and activate downstream signalling pathways. Crosstalk with other signalling pathways ensures that the TLR signal is properly regulated and leads to apoptosis or cell survival, and the transcription of pro-inflammatory cytokines and chemokines, and type I interferons (IFNs). CD14, a coreceptor for LPS; LBP, LPS-binding protein; LPS, lipopolysaccharide; MAL/TIRAP, MYD88 adaptor-like protein; MD2, myeloid differentiation factor 2; PKC $\varepsilon$, protein kinase C $\varepsilon$; TAK-242, TLR4 inhibitor; TRAM, TRIF-related adaptor molecule. Image and legend adapted from [1]

domain, abrogated polymer formation. A third variant, L252P in the TIR domain, is of particular interest because it is found as a dominant somatic mutation in many B-cell lymphomas [7]. The presence of L252P causes stimulus-independent activation of MyD88directed signals and constitutive activation of $\mathrm{NFkB}$, conferring a pro-survival phenotype in these tumours. Interestingly L252P MyD88 formed lower order oligomers compared to the wild-type but the formation of these short oligomers had a critical threshold of $2 \mathrm{nM}$, about 40-fold lower than that of the wild type. This result is consistent with previous studies indicating that the L252P MyD88 was able to form signalling myddosomes at endogenous concentrations in the absence of a nucleating signal from an activated TLR [8].

A key question unanswered by this study is the stoichiometry of endogenous MyD88 in unstimulated cells. Overexpression of MyD88 leads to the appearance of speckles in the cytosol, likely caused by oligomerisation, but endogenous MyD88 appears to be uniformly distributed. This might indicate that it forms only short oligomers rather than filaments or perhaps that it is monomeric. One published study provides evidence that MyD88 is monomeric or possibly dimeric in lysates prepared from resting cells, but this conclusion may be unreliable as preparation of the lysates could cause significant dilution of the MyD88 [9]. A more direct measurement of stoichiometry might be possible using single molecule imaging or super resolution microscopy.

The role played by oligomers and filaments in innate immune signal transduction has been an emerging theme over the last few years. These structures have been described as supra-molecular organising centres and are formed during activation of the TLR-TRIF and inflammasome NLRP3-ASC-Caspase1 pathways as well as in pro-inflammatory signalling through MyD88 [10]. A recent study solved the structure of a filament formed by another signalling adaptor protein that enhances signal transduction by TLR2 and TLR4, Mal/TIRAP [3]. Although the filaments produced by Mal/TIRAP in vitro are unlikely to represent a signalling scaffold in vivo, this study nevertheless identified TIR-TIR interactions that are probably critical for potentiating MyD88-driven signals. The study of Gambin and colleagues suggests 

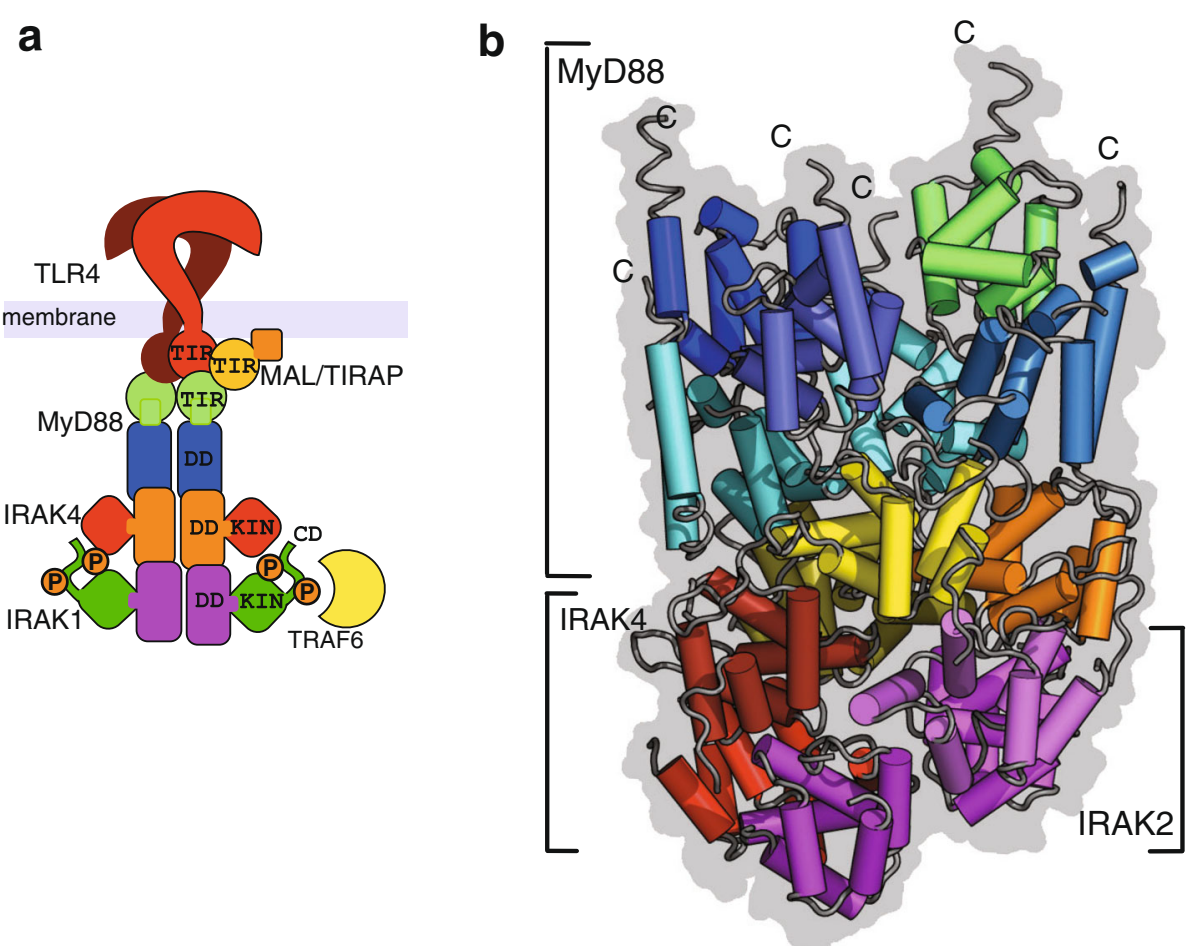

Fig. 2. Death domain and TIR assemblies in Toll signalling through the myddosome. a An activated dimeric Toll-like receptor 4 (TLR4) showing the arrangement of its cytosolic TIR domains in association with Myd88 TIR domains, MyD88 death domains (DD), and interleukin-1 receptorassociated kinase (IRAK) kinase domains (KIN). b The myddosome DD assembly is shown with six MYD88 DDs (blues and green), four IRAK4 DDs (red, orange and yellow) and four IRAK2 DDs (violet). Image and legend adapted from [1]

that oligomers formed by other TLR signal transducers are also critical for signalling function. Structural analysis of the oligomers and filaments formed by both the full length MyD88 and the DD alone will provide further insights into the mechanism by which activated receptors nucleate TLR signalling as well as the role of auto-inhibition and polymerisation in this critical cellular process. It is also likely that small molecule inhibitors that target interfaces required for filament assembly can be developed as novel anti-inflammatory drugs.

\section{Acknowledgements}

Not applicable.

\section{Funding}

Wellcome Trust Investigator award (WT100321///12/) to NJG.

\section{Availability of data and materials}

Not applicable.

\section{Author's contribution}

NJG wrote the commentary, and read and approved the final version.

\section{Competing interests}

The author declares that he has no competing interests.

\section{Publisher's Note}

Springer Nature remains neutral with regard to jurisdictional claims in published maps and institutional affiliations.

Published online: 20 February 2019

\section{References}

1. Gay NJ, Symmons MF, Gangloff M, Bryant CE. Assembly and localization of toll-like receptor signalling complexes. Nat Rev Immunol. 2014;14:546-58.

2. Latty SL, Sakai J, Hopkins L, Verstak B, Paramo T, Berglund NA, et al. Activation of toll-like receptors nucleates assembly of the MyDDosome signaling hub. Elife. 2018;7:e31377.

3. Ve T, Vajjhala PR, Hedger A, Croll T, DiMaio F, Horsefield $S$, et al. Structural basis of TIR-domain-assembly formation in MAL- and MyD88-dependent TLR4 signaling. Nat Struct Mol Biol. 2017;24: 743-51.

4. Motshwene PG, Moncrieffe MC, Grossmann JG, Kao C, Ayaluru M, Sandercock AM, et al. An oligomeric signaling platform formed by the toll-like receptor signal transducers MyD88 and IRAK-4. J Biol Chem. 2009;284:25404-11

5. O'Carroll A, Chauvin B, Brown JW, Meagher A, Coyle J, Schill J, et al. Pathological mutations differentially affect the self-assembly and polymerisation of the innate immune system signaling adaptor molecule MyD88. BMC Biol. 2018;16:149. https://doi.org/10.1186/ s12915-018-0611-7.

6. Lin SC, Lo YC, Wu H. Helical assembly in the MyD88-IRAK4-IRAK2 complex in TLR/IL-1R signalling. Nature. 2010:465:885-90.

7. Ngo VN, Young RM, Schmitz R, Jhavar S, Xiao W, Lim KH, et al. Oncogenically active MYD88 mutations in human lymphoma. Nature. 2011;470:115-9. 
8. Avbelj M, Wolz OO, Fekonja O, Bencina M, Repic M, Mavri J, et al. Activation of lymphoma-associated MyD88 mutations via allosteryinduced TIR-domain oligomerization. Blood. 2014;124:3896-904.

9. Nishiya T, Kajita E, Horinouchi T, Nishimoto A, Miwa S. Distinct roles of TIR and non-TIR regions in the subcellular localization and signaling properties of MyD88. FEBS Lett. 2007;581:3223-9.

10. Kagan JC, Magupalli VG, Wu H. SMOCs: supramolecular organizing centres that control innate immunity. Nat Rev Immunol. 2014;14:821-6.

Ready to submit your research? Choose BMC and benefit from:

- fast, convenient online submission

- thorough peer review by experienced researchers in your field

- rapid publication on acceptance

- support for research data, including large and complex data types

- gold Open Access which fosters wider collaboration and increased citations

- maximum visibility for your research: over $100 \mathrm{M}$ website views per year

At $B M C$, research is always in progress.

Learn more biomedcentral.com/submissions 